\title{
Helge Thun
}

\section{Interview}

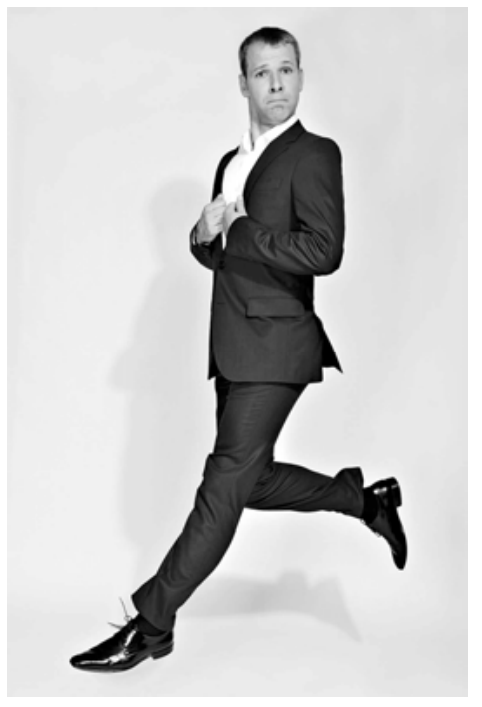

(C) Reiner Pfisterer

Geboren 1971 in Kiel. Highschooljahr in den USA, Abitur in Eutin, Studium der Germanistik/ Amerikanistik in Tübingen. Seit 1995 erfolgreicher Studienabbrecher: u. a. Schauspieler (Landestheater Tübingen 1995-98), mehrfacher internationaler Preisträger der Zauberkunst, professioneller Improspieler, Comedian, Kabarettist und komischer Dichter. 
Welches waren oder sind für Sie wichtige Inspirationsquellen und Vorbilder im Bereich des Spielens mit Wörtern und Sprache?

Die üblichen Verdächtigen, aber speziell drei:

- Heinz Erhardt: genial, wie er in seinen Gedichten die Fallhöhe zwischen hohem, pathetischem oder lyrischem Tonfall mit umgangssprachlichen, banalen Pointen („Das Gewitter“) oder Themen („Die Made“) kontrastiert. Und sein meisterhafter Vortrag ist in Rhythmus, Timing und Ausdruck bis heute unübertroffen!

- Robert Gernhardt: durch Otto Waalkes bin ich früh mit seinen genialen Wortspiel-Gedichten wie dem „Inselpfarrer“ oder grandiosen absurdalbernen Sketchen („Das Wunder des Ärgerns“) in Berührung gekommen.

- Erich Kästner: unglaublich, wie sachlich und lakonisch-umgangssprachlich er in perfektem Versmaß und Reimschema schreiben konnte. Als wäre es Prosa, die sich zufällig, ja fast beiläufig reimt. Die Gleichzeitigkeit von Tragik und Komik wie in „Die Ballade vom Nachahmungstrieb“ gelingt niemandem so unangestrengt wie ihm.

Inwiefern spielen andere Sprachen, Mehrsprachigkeit, Sprachenvielfalt und Übersetzungsprozesse in Ihren wortspielerischen Werken eine wichtige Rolle?

Inspiriert durch Otto Waalkes’ „English for runaways“ entstanden vor allem zwei Bühnensketche mit falscher Wortspiel-Übersetzung, eine französische Szene „Tour de France“ und ein italienischer Sketch „Lucky Luciano“. Da es sich bei beiden Sketchen um begleitende Texte für Zaubernummern handelt, die sich ohne die entsprechenden Kunststücke nicht von alleine erklären, hier nur zur Verdeutlichung des Prinzips zwei kurze Beispiele:

Tour de France

$[\ldots]$

Ich mache einen Knoten hier - je fais une Knot' couture

- und einen Knoten hier - et une Knot' Azur

[...]

Lucky Luciano

[...]

Sind sie bereit fürs Schießen? - Cinquecento prosciutto?

- Mortadella! - Tod durch Cellulite! 
Inwiefern ergibt sich für Sie durch das Spielen mit Wörtern die Möglichkeit, die Ausdrucksmöglichkeiten der Sprache und des Wortschatzes zu erweitern?

Eigene Wortschöpfungen oder Abwandlungen können das Reimspektrum erweitern und ein Gedicht unvorhersehbarer und überraschender machen:

Romeo und Julia

[...]

Sie war verknallt und er verknällter

und sie wurden auch nicht älter

[...]

Können Sie abschließend ein Beispiel für einen eigenen wortspielerischen Text geben?

Da ein Wortspiel immer ein Spiel mit der Sprache selbst ist, üben ganze Texte bzw. komplette Szenen und Sketche, die sich auf einer selbstbezüglichen Ebene um die Sprache selbst drehen, schon immer einen besonderen Reiz auf mich aus. Der Text um eine „schwere Geburt“, in dem das „Schwanger Gehen“ mit einer Idee und die „Geburt“ eines Textes wörtlich genommen werden, ist daher schon länger einer meiner persönlichen Favoriten:

Die schwere Geburt (Auszüge)

ZWEI: Sag mal, hast Du zugenommen?

EINS: Was?

ZWEI: Ich seh' da grad' so'n Bauchansatz und ich merk's ja auch am Platz, den du auf der Bühne brauchst, dass du in der Mitte „bauchst“.

EINS: Und? Bin ich jetzt vom Umfang her für den Herrn kein Umgang mehr? Ist ihm der Partner jetzt zu dicklich?

ZWEI: Ach fi ... vielleicht! Jetzt komm und krieg Dich wieder ein! Du stehst ja nicht am Pranger!

EINS: Ich bin nicht dick, ich bin bloß schwanger.

ZWEI: Sehr witzig! Du bist also jetzt 'ne Frau!? 
EINS: Genau! Ach Quatsch. Mein Körperbau

hat sich nun mal leicht erweitert, was dich scheinbar leicht erheitert, weil ich seit längerem mit 'ner Idee $\mathrm{zu}$ 'ner Geschichte schwanger geh.

$[\ldots]$

ZWEI: Presse! Presse! Presse!

Raus mit der Sprache! Du schaffst es!

Das wird ein ganz, ganz zauberhaftes

Sonett, ein Gedicht, ein poetisches Lied!

Ein Sketch, ein Rap mit Beatbox-Beat.

EINS (holt Blatt Papier hervor): Mensch, jetzt laber hier nicht voll mich!

Aaaaaaarghhh!!!

ZWEI: Ach guck mal süß! Wie goldig!

Gratuliere! Das hast Du toll gemacht!

'Nen gesunden Text zur Welt gebracht.

EINS: Was ist es? Hellblau oder Rosa?

Ein junger Text, ein Mädchen in Prosa?

ZWEI: Es sieht ganz danach aus als wär's 'n

Geburtsgedicht in Knittelversen.

Die Reime mal männlich mal weiblich, da wird es dann aber auch Zeit, sich

zu überlegen, wie es heißen soll.

Ob Nils, ob Niko oder Nicole,

ob Kathrin, ob Katja, ob Kurt?

EINS: Nee, das nenn’ ich „Ne schwere Geburt“!

(zuerst erschienen in: Helge Thun, Wollte Waldemar wegen Wetter warnen. Tübingen: Klöpfer \& Meyer, 2015, 114-118) 